\title{
Quality of life and personality traits in patients with malignant pleural mesothelioma and their first-degree caregivers
}

This article was published in the following Dove Press journal:

Neuropsychiatric Disease and Treatment

13 August 2013

Number of times this article has been viewed

\author{
Antonella Granieri' \\ Stella Tamburello ${ }^{2}$ \\ Antonino Tamburello ${ }^{2}$ \\ Silvia Casale ${ }^{3}$ \\ Chiara Cont ${ }^{1}$ \\ Fanny Guglielmucci' \\ Marco Innamorati \\ 'Università degli Studi di Torino, Turin, \\ Italy; ${ }^{2}$ Università Europea di Roma, \\ Rome, Italy; ${ }^{3}$ Università di Firenze, \\ Firenze, Italy
}

\begin{abstract}
Asbestos exposure causes significant pleural diseases, including malignant pleural mesothelioma (MPM). Taking into account the impact of MPM on emotional functioning and wellbeing, this study aimed to evaluate the quality of life and personality traits in patients with MPM and their first-degree caregivers through the World Health Organization Quality of LifeBREF (WHOQOL-BREF) and the Minnesota Multiphasic Personality Inventory-2 Restructured Form (MMPI-2-RF). The sample was composed of 27 MPM patients, 55 first-degree relatives enrolled in Casale Monferrato and Monfalcone (Italy), and 40 healthy controls (HC). Patients and relatives reported poorer physical health than the HC. Patients had a higher overall sense of physical debilitation and poorer health than relatives and the $\mathrm{HC}$, more numerous complaints of memory problems and difficulties in concentrating, and a greater belief that goals cannot be reached or problems solved, while often claiming that they were more indecisive and inefficacious than the HC. First-degree relatives reported lower opinions of others, a greater belief that goals cannot be reached or problems solved, support for the notion that they are indecisive and inefficacious, and were more likely to suffer from fear that significantly inhibited normal activities than were HC. In multinomial regression analyses, partial models indicated that sex, physical comorbidities, and the True Response Inconsistency (TRIN-r), Malaise (MLS), and Behavior-Restricting Fears (BRF) dimensions of the MMPI-2-RF had significant effects on group differences. In conclusion, health care providers should assess the ongoing adjustment and emotional wellbeing of people with MPM and their relatives, and provide support to reduce emotional distress.
\end{abstract}

Keywords: asbestos, cancer, MMPI-2-RF, Casale Monferrato, Monfalcone, Italy

\section{Introduction}

Asbestos is a generic term used to identify a number of well-known silicate minerals, which may produce thin and flexible fibers when crushed; in the last century asbestos was extensively used because of its thermoelectrical and sound absorptive properties, as well as its resistance to chemical and biological agents. ${ }^{1}$ Asbestos exposure is responsible for several pleural diseases, including pleural plaques, diffuse pleural thickening, benign asbestos-related pleural effusions, and malignant pleural mesothelioma (MPM). ${ }^{2}$

MPM is a rare and rapidly fatal tumor that is closely related to the inhalation of asbestos fibers and accounts for approximately $1 \%$ of all cancer deaths in the world. ${ }^{3}$ In Italy, the Italian National Register, the national surveillance system of MPM, recorded a case list of 8,868 MPM between 1993 and 2004, equivalent to standardized incidence rates of 3.49 per 100,000 inhabitants for men and 1.25 for women, with a wide interregional variability. ${ }^{4}$

\footnotetext{
Department of Psychology,

University of Turin, Via Po I4,

I0I23 Turin, Italy

Tel +390110913062

Fax +390118146231

Email antonella.granieri@unito.it

Correspondence: Antonella Granieri
}

submit your manuscript $\mid$ www.dovepress.con

Dovepress 
MPM is recognized as a disease that is mostly associated with occupational exposure, though in some cases, the exposure may occur in the environment near industrial or natural sources of asbestos. Cases of indirect exposure can also be found among those who live with people who are occupationally exposed to asbestos. ${ }^{5}$ In Italy, Marinaccio et $\mathrm{al}^{4}$ reported that over $69 \%$ of the patients with MPM they interviewed had been exposed to asbestos in an occupational setting; $4.4 \%$ of patients were the result of cohabitating with someone who was occupationally exposed; and $6 \%$ of the respondents were exposed to asbestos through the general environment or leisure activities.

Despite advances in chemotherapy, radiotherapy, and surgical approaches, MPM remains largely resistant to treatment, with an estimated median survival time of 9 months. ${ }^{6}$ The impact of MPM is multidimensional and is associated with several physical symptoms (eg, pain, breathlessness, fatigue, cough, sleep disturbance, appetite loss, and sweating), lower emotional functioning (eg, anxiety, depression, fear, and isolation), and changes in social roles and interpersonal relationships. ${ }^{7}$

Despite MPM's severe impact on emotional functioning and the wellbeing of individuals and their families, most information about the quality of life (QoL) of patients with MPM and their caregivers is anecdotal, and systematic studies are rare. Recently, the British Lung Foundation (BLF) survey of MPM patients and their caregivers indicated that emotional functioning in patients with MPM and their family members is significantly impaired. ${ }^{8,9}$ Furthermore, caregivers reported higher levels of personal distress than did patients, received less guidance and support, and were far less likely to feel well-informed throughout the process of diagnosis. ${ }^{8}$

Thus, the aim of this study was to investigate both the QoL and personality of patients with MPM and their caregivers (ie, the relatives or family members who provide direct care to the person with MPM). We hypothesized that both patients with MPM and their relatives who provide direct care and support may have a poor QoL.

\section{Methods}

\section{Design and procedure}

This was a cross-sectional study investigating QoL in patients with MPM and their caregivers. The cases used in this study involved patients with MPM who lived in Casale Monferrato and Monfalcone. To enroll cases, flyers were sent to some nonprofit organizations that were active in Casale Monferrato and Monfalcone, such as the Relatives and Victims of Asbestos Association, the Exposed to Asbestos Association, and the Work Invalids and Maimed National Association. Furthermore, the researchers contacted physicians of the Santo Spirito Hospital in Casale Monferrato, who publicized the research to their patients. Casale Monferrato and Monfalcone were selected as centers to enroll patients because in these towns there are the most important facilities for the treatment of asbestos in Italy.

In order to be included in the study patients had to be 18 years of age and over and be diagnosed with MPM. Patients were excluded if they were at the terminal stage of the disease, had any disease of the central nervous system or major medical comorbidities (eg, diabetes, cardiac disease, or non-MPM tumors that were or were not associated with asbestos exposure), or any diagnosis on Axis I or Axis II of the Diagnostic and Statistical Manual of Mental Disorders, fourth edition-text revised (DSM-IV-TR) ${ }^{10}$ First-degree relatives were expected to live in the same geographical areas of the patients, be 18 years or older, and provide direct care and support to the person with MPM. First-degree relatives were excluded from the study if they had any disease of the central nervous system, major medical conditions including MPM or other diseases associated with asbestos exposure, or any DSM-IV-TR diagnosis. ${ }^{10}$

Controls were selected using judgmental sampling in towns homogeneous to Casale Monferrato and Monfalcone for geographical area, population density and demographic stratification. Subjects were recruited among people who were not exposed to asbestos, using flyers that were sent to nonprofit organizations that were active in both areas. The same inclusion/exclusion criteria as for first-degree relatives were used for the control group.

All subjects participated anonymously in the study and gave their informed consent. The study protocol was approved by the local Institutional Review Board (IRB).

\section{Participants}

In total, 153 subjects were enrolled in the study, but 19 patients ( $12 \%$ of the total) died before the assessment was complete. Similarly, 12 subjects ( $8 \%$ of the total) were excluded because they either did not complete the World Health Organization Quality of Life-BREF (WHOQOL-BREF) ${ }^{12}$ (31\%) or the Minnesota Multiphasic Personality Inventory-2 Restructured Form (MMPI-2-RF) ${ }^{13}(32 \%)$, or because they had an invalid profile in the MMPI-RF (37\%).

The final sample was composed of 27 patients (eight women and 19 men) affected by MPM, with a mean age of $61.41 \pm 8.82$ years; 55 first-degree relatives (43 women and 12 men), with a mean age of $56.51 \pm 13.66$ years; 
and 40 healthy controls ( 22 women and 18 men), with a mean age of $44.63 \pm 13.02$ years.

All the patients had occupational exposure to asbestos. The diagnosis of MPM was made between January and June 2010, and they all claimed to have received treatment for MPM, including surgery, radiotherapy, chemotherapy, and immunotherapy. ${ }^{11}$

\section{Measures}

Subjects were administered the WHOQOL-BREF ${ }^{12}$ in order to measure QoL, and the MMPI-2-RF. ${ }^{13}$ The WHOQOLBREF is a 26 item self-report questionnaire measuring four broad domains of QoL: physical health, psychological health, social relationships, and environmental health.

The MMPI-2-RF is a revised, 338-item version of the MMPI-2 that is conceptually and empirically linked to modern theories and models of psychopathology and personality. It is composed of 51 scales: nine validity scales, three higher-order scales, nine restructured clinical scales (RC), five somatic/cognitive scales, nine internalizing scales, four externalizing scales, five interpersonal scales, two interest scales, and five personality psychopathology scales (see Table 1 for descriptions of the dimensions). The Italian adaptation of the MMPI-2-RF has psychometric properties that have been found to be comparable to those of the American version. ${ }^{14}$ Factor analyses on the higher-order and the $\mathrm{RC}$ scales conducted on a 1,234 normative sample and 464 psychiatric patients confirmed the factorial structure of the original version. Moreover, internal consistency estimates were comparable to those found with the American population, and good discriminant and concurrent validity were found. ${ }^{14}$

\section{Statistical analysis}

Chi-squared tests $\left(\chi^{2}\right)$ and analysis of variance tests (ANOVA) were used for bivariate analyses. Benjamini and Hochberg's correction was used for multiple testing. ${ }^{15}$ When ANOVAs were significant after correction for multitesting, we used Tamhane's $T 2$ tests for post hoc comparisons among groups. All variables that were significant at the bivariate analyses after correction for multitesting were inserted as independent variables in a series of multinomial regression analyses with groups as criteria. Due to the higher number of variables included in the study and the lower number of subjects included in some groups, we performed three analyses with single blocks of variables: in the first model, we inserted sociodemographic variables; in the second model, we inserted the validity scales of the MMPI-2-RF; and in the third model, we inserted the clinical scales of the MMPI2-RF. In a final model, we inserted all the variables that had been significant in the previous analyses and the WHOQOL Physical Health. As measures of model fit, we reported the $-2 \log$ likelihood statistic ( -2 LL), the likelihood $\chi^{2}$, and the Pearson's $\chi^{2}$. As measures of effects significance, we reported the -2 LL for reduced model and the likelihood ratio test. As measures of association, we reported odds ratios (OR) and their 95\% confidence intervals (CI). ORs greater than 1 indicated a higher risk for patients or their relatives when compared with healthy controls.

All the analyses were performed with the statistical package for the social sciences SPSS for Windows 19.0 (IBM, Armonk, NY, USA).

\section{Results \\ Differences among groups}

Table 2 lists the sociodemographic characteristics of the groups. Groups differed for most sociodemographic variables even after the correction for multitesting. The healthy controls (compared with the other groups) were younger, more likely to be women, more likely to live alone, and were less likely to have had low school attainment. The controls also had a lower rate of physical comorbidities than did the other groups. Finally, the groups did not differ in terms of employment.

The groups differed only on one single dimension of the WHOQOL (see Table 3). Both patients and their relatives reported poorer physical health than did the healthy controls. Despite this, the raw scores on psychological health and environmental health were lower for patients and their relatives than for controls. The differences were not significant after controlling for multitesting.

The groups also differed on several dimensions of the MMPI-2-RF (see Table 4). Patients had a higher overall sense of physical debilitation and poorer health (MLS) than did first-degree relatives and healthy controls and complained of memory problems and difficulties in concentrating (COG) more often than did the healthy controls. They were also more likely to believe that goals cannot be reached or problems solved (HLP) and that they were more indecisive and inefficacious (NFC) than were the healthy controls.

First-degree relatives of patients reported lower opinions of others (RC3), were more likely to believe that goals cannot be reached or problems solved (HLP) and often thought themselves to be more indecisive and inefficacious (NFC) than did the healthy controls (see Table 4). Furthermore, they were more likely to report the presence of fears that 
Table I Acronyms and description of each dimension of the Minnesota Multiphasic Personality Inventory-2 Restructured Form (MMPI-2-RF)

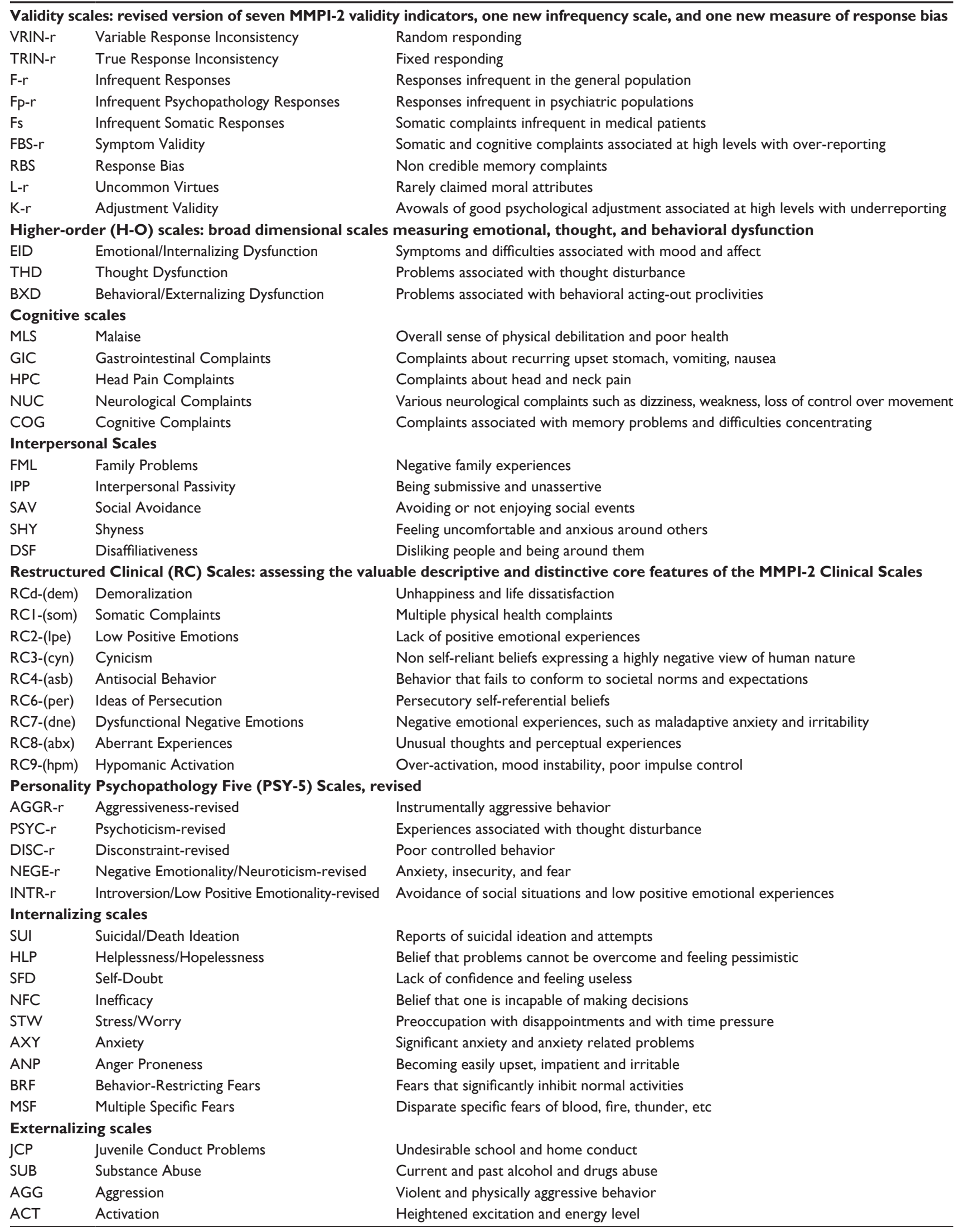


Table I (Continued)

\begin{tabular}{lll}
\hline Interest scales & \\
AES & Aesthetic-Literary Interests & Interest about activities such as theatre or music \\
MEC & Mechanical-Physical Interests & Interests about activities such as fixing and building things \\
\hline
\end{tabular}

significantly inhibit normal activities (BRF) than were the healthy controls.

There were also differences in the validity scales of the MMPI-2-RF (see Table 3). Patients and their first-degree relatives had higher scores on True Response Inconsistency (TRIN-r), Infrequent Responses (F-r), Infrequent Somatic Responses (Fs), and Symptom Validity (FBS-r) than did the controls. Thus, these groups endorsed "true" response more incoherently (fixed responding), and they more frequently endorsed responses that were infrequent in the general population, somatic complaints that were infrequent in medical populations, and somatic and cognitive complaints associated with higher levels of overreporting.

All the variables significant at the bivariate analyses were inserted as independent variables in a series of multinomial regression analyses, with groups as criteria (see Tables 5 and 6). The partial models indicated that sex, physical comorbidities, and the TRIN-r, MLS, and BRF dimensions of the MMPI-2-RF had significant effects on group differences (see Table 5). These variables were inserted into a final model, which fitted the data well and explained $66 \%$ of the variability of the data (Nagelkerke $R^{2}=0.66$ ) (see Table 6).

In the final model, all the independent variables, except for the BRF and physical health, had a significant effect on group differences. Patients (compared with healthy controls) were: less likely to be women $(\mathrm{OR}=0.12 ; 95 \% \mathrm{CI}$ : $0.02-0.78)(P<0.05)$; less likely to live alone $(\mathrm{OR}=0.08$; 95\% CI: $0.01-0.51)(P<0.01)$; more likely to have physical comorbidities $(\mathrm{OR}=27.43 ; 95 \% \mathrm{CI}: 3.17-237.50)$
$(P<0.01)$; and more likely to report higher scores on the TRIN-r $(\mathrm{OR}=1.99 ; 95 \% \mathrm{CI}: 1.22-3.22)(P<0.01)$ and on the MLS (OR $=1.88 ; 95 \%$ CI: $1.15-3.08)(P<0.05)$. First-degree relatives (compared with healthy controls) were: less likely to live alone $(\mathrm{OR}=0.20$; $95 \%$ CI: $0.05-0.80)$ $(P<0.05)$; and more likely to have had lower amounts of schooling $(\mathrm{OR}=5.16 ; 95 \% \mathrm{CI}: 3.17-237.50)(P<0.05)$.

\section{Discussion}

Previous studies have indicated that family members of patients with cancer - particularly spouses - share many caregiving tasks. ${ }^{16,17}$ In our sample, patients with MPM were frequently men who were over 50 -years-old. Their caregivers were frequently women who were over 50-years-old, indicating that the MPM patients' wives were the ones who provided direct care to their relatives.

The sociodemographic characteristics of our sample are concordant with those of the sample that participated in the BLF survey. ${ }^{8}$ In fact, MPM was most commonly contracted by adult individuals working in male-dominated trades or industries during the period in which asbestos was most frequently used.

Patients with MPM reported significantly poorer physical health on the WHOQOL and higher scores on the MMPI-2-RF MLS (overall sense of physical debilitation and poor health) and COG (complaints associated with memory problems and difficulties concentrating) scales than did controls, and almost all had physical comorbidities. MPM patients also had lower scores on all areas of QoL investigated with the WHOQOL

Table 2 Sociodemographic characteristics of the groups

\begin{tabular}{|c|c|c|c|c|c|c|c|c|}
\hline \multirow[t]{3}{*}{ Variables } & \multirow{3}{*}{$\begin{array}{l}\text { I } \\
\text { Patients } \\
(N=27)\end{array}$} & \multirow{3}{*}{$\begin{array}{l}2 \\
\text { First-degree caregivers } \\
(N=55)\end{array}$} & \multirow{3}{*}{$\begin{array}{l}3 \\
\text { Healthy controls } \\
(N=40)\end{array}$} & \multirow[t]{3}{*}{ Test } & \multirow[t]{3}{*}{$\mathbf{P}<$} & \multirow{2}{*}{\multicolumn{3}{|c|}{$\begin{array}{l}\text { Post hoc tests } \\
\text { Mean difference }\end{array}$}} \\
\hline & & & & & & & & \\
\hline & & & & & & 12 & 13 & 23 \\
\hline Women & $29.6 \%$ & $78.2 \%$ & $55.0 \%$ & $\chi_{2}^{2}=18.34$ & $<0.001 * *$ & & & \\
\hline Age & $61.41 \pm 8.82$ & $56.51 \pm 13.66$ & $44.63 \pm 13.02$ & $F_{2 ; 119}=16.95$ & $<0.001 * *$ & 4.90 & $16.78^{*}$ & II.88* \\
\hline Living alone & 48.0 & 56.4 & 90.0 & $\chi_{2}^{2}=16.11$ & $<0.001^{* *}$ & & & \\
\hline School $\leq 8$ years & 60.0 & 47.3 & 7.5 & $\chi_{2}^{2}=23.18$ & $<0.00 I^{* *}$ & & & \\
\hline Job & & & & $\chi_{4}^{2}=6.76$ & 0.15 & & & \\
\hline Employed & 88.5 & 75.5 & 75.5 & & & & & \\
\hline Unemployed & 7.7 & 3.8 & 3.8 & & & & & \\
\hline Other & 3.8 & 20.8 & 20.8 & & & & & \\
\hline Physical comorbidities & 92.0 & 59.3 & 30.8 & $\chi_{4}^{2}=23.52$ & $<0.001^{* *}$ & & & \\
\hline
\end{tabular}

Notes: Benjamini-Hochberg correction for multitesting. *Significant for $P<0.05$; **significant for $P<0.01$. Tamhane's post hoc tests. 
Table 3 WHOQOL and validity scales of the MMPI-RF

\begin{tabular}{|c|c|c|c|c|c|c|c|c|}
\hline \multirow[t]{3}{*}{ Variables } & \multirow{3}{*}{$\begin{array}{l}\text { I } \\
\text { Patients } \\
(\mathbf{N}=27)\end{array}$} & \multirow{3}{*}{$\begin{array}{l}2 \\
\text { First-degree relatives } \\
(\mathrm{N}=55)\end{array}$} & \multirow{3}{*}{$\begin{array}{l}3 \\
\text { Healthy controls } \\
(N=40)\end{array}$} & \multirow[t]{3}{*}{ Test } & \multirow[t]{3}{*}{$\mathbf{P}<$} & \multirow{2}{*}{\multicolumn{3}{|c|}{$\begin{array}{l}\text { Post hoc tests } \\
\text { Mean difference }\end{array}$}} \\
\hline & & & & & & & & \\
\hline & & & & & & 12 & 13 & 23 \\
\hline \multicolumn{9}{|l|}{ WHOQOL } \\
\hline Physical health & $57.28 \pm 15.83$ & $63.95 \pm 14.54$ & $75.40 \pm 11.58$ & $F_{2 ; 119}=14.75$ & $<0.00 I^{* *}$ & -6.67 & $-18.12^{*}$ & $-11.45^{*}$ \\
\hline Psychological health & $57.37 \pm 15.34$ & $61.09 \pm 13.48$ & $65.83 \pm 10.77$ & $F_{2 ; 119}=3.47$ & 0.03 & & & \\
\hline Social health & $62.50 \pm 18.14$ & $65.53 \pm 14.97$ & $69.17 \pm 16.47$ & $F_{2 ; 119}=1.39$ & 0.25 & & & \\
\hline Environmental health & $57.01 \pm 16.20$ & $56.23 \pm 14.80$ & $64.53 \pm 11.73$ & $F_{2 ; 119}=4.32$ & 0.02 & & & \\
\hline \multicolumn{9}{|l|}{ Validity scales } \\
\hline VRIN-r & $5.04 \pm 2.88$ & $4.84 \pm 2.43$ & $4.30 \pm 2.44$ & $F_{2 ; 119}=0.81$ & 0.45 & & & \\
\hline TRIN-r & $12.96 \pm 2.43$ & $11.96 \pm 2.03$ & $10.63 \pm 1.55$ & $F_{2 ; 119}=11.80$ & $<0.001 * *$ & 1.00 & $2.34 *$ & $\mathrm{I} .34 *$ \\
\hline F-r & $6.11 \pm 4.29$ & $5.04 \pm 4.30$ & $3.13 \pm 3.28$ & $F_{2 ; 119}=4.98$ & $0.008 *$ & 1.08 & $2.99 *$ & $1.91 *$ \\
\hline Fp-r & $2.22 \pm 1.95$ & $2.25 \pm 1.83$ & $2.25 \pm 1.63$ & $F_{2 ; 119}=0.003$ & 1.00 & & & \\
\hline Fs & $3.48 \pm 2.23$ & $2.35 \pm 2.14$ & $1.18 \pm 1.65$ & $F_{2 ; 119}=10.83$ & $<0.00 I^{* *}$ & 1.14 & $2.3 I^{*}$ & $1.17 *$ \\
\hline FBS-r & $11.74 \pm 3.46$ & $10.38 \pm 4.48$ & $8.10 \pm 3.52$ & $F_{2 ; 119}=7.40$ & $0.001 * *$ & 1.36 & $3.64 *$ & $2.28^{*}$ \\
\hline L-r & $5.44 \pm 2.04$ & $5.55 \pm 2.10$ & $5.03 \pm 2.85$ & $F_{2 ; 119}=0.59$ & 0.56 & & & \\
\hline K-r & $6.00 \pm 2.50$ & $5.87 \pm 2.88$ & $7.50 \pm 2.91$ & $F_{2 ; 119}=4.30$ & 0.02 & & & \\
\hline
\end{tabular}

Notes: Benjamini-Hochberg correction for multitesting. *Significant for $P<0.05$; **significant for $P<0.01$. Tamhane's post hoc tests.

Abbreviations: F-r, Infrequent Responses; FBS-r, Symptom Validity; Fp-r, Infrequent Psychopathology Responses; Fs, Infrequent Somatic Responses; K-r, Adjustment Validity; L-r, Uncommon Virtues; MMPI-RF, Minnesota Multiphasic Personality Inventory-2 Restructured Form; TRIN-r, True Response Inconsistency; VRIN-r, Variable Response Inconsistency; WHOQOL, World Health Organization Quality of Life.

(emotional, social, and environmental health), but the differences did not reach statistical significance. Nevertheless, the differences in QoL between patients with MPM and controls were moderate in terms of both Psychological Health and Environmental Health (Cohen's $D=0.53$ [for Environmental Health] to 0.64 [for Psychological Health]), with MPM patients complaining of poorer health. We did not directly investigate the presence of affective symptomatology, mood disturbances, and chronic pain, or emotions such as sadness, grief, anger, and anxiety. ${ }^{18}$ Such emotions may not have been associated only with illness per se, but possibly also with the fact that most of them were exposed to asbestos prior to the implementation of occupational safety standards - thus, patients and families may have felt anger towards employers who did not inform them of these types of environmental and workplace hazards. ${ }^{18}$ Finally, it has been seen that patients and families have distress linked to lengthy legal battles, as they seek financial compensation from their employers for having developed an occupationally associated illness. ${ }^{18}$ In the BLF survey of MPM patients and their caregivers, approximately one out of two patients with MPM reported feeling depressed some or most of the time since diagnosis, $67 \%$ of them reported feeling anxiety some or most of the time, and $59 \%$ reported feeling fear. ${ }^{8}$

The caregivers of MPM patients also reported poorer physical health than did the controls, and frequent comorbidities with physical illness. ${ }^{17}$ Their scores on other areas of QoL, as measured by the WHOQOL, were constantly higher than those of patients but lower than those of controls, except for environmental health, where they had the lowest raw scores and where the difference between them and controls was moderate, although not significant (Cohen's $D=0.62$ ). This data could be linked to the fact they had been exposed to the fibers for years and now live in fear of succumbing to illness due to their long exposure to the carcinogenic stimulus. ${ }^{19}$

Our results are somewhat inconsistent with those of the BLF survey of MPM patients and their caregivers, in which more caregivers than patients with MPM reported that they had felt depressed since the diagnosis (around $80 \%$ of caregivers reported feeling depressed some or most of the time). The BLF survey suggested that feeling isolated was another common emotion among the caregivers of MPM patients (in that study, around $78 \%$ of caregivers reported feeling isolated/alone some or most of the time). In our sample, the caregivers reported a poorer perception of the environment and significantly higher scores than did controls in the RC3. Caregivers typically display increasingly cynical behavior and are often unable to understand the selflessness and helpfulness of others, many of which are perceived as being alien and less inclined to help and provide support to the patient. The content of this scale focuses on a cynical view of human nature and a generally negative view of the motivations of other people, reflecting the key idea that other people are looking out for their own interests most of the time and cannot be trusted. ${ }^{20}$ 
Table 4 Personality profile broken down by group

\begin{tabular}{|c|c|c|c|c|c|c|c|c|}
\hline \multirow[t]{2}{*}{ Variables } & \multirow{2}{*}{$\begin{array}{l}\text { I } \\
\text { Patients } \\
(\mathbf{N}=27)\end{array}$} & \multirow{2}{*}{$\begin{array}{l}2 \\
\text { First-degree relatives } \\
(\mathrm{N}=55)\end{array}$} & \multirow{2}{*}{$\begin{array}{l}3 \\
\text { Healthy controls } \\
(\mathbf{N}=40)\end{array}$} & \multirow[t]{2}{*}{ Test } & \multirow[t]{2}{*}{$\mathbf{P}<$} & \multicolumn{3}{|c|}{$\begin{array}{l}\text { Post hoc tests } \\
\text { Mean difference }\end{array}$} \\
\hline & & & & & & 12 & 13 & 23 \\
\hline \multicolumn{9}{|c|}{ MMPI-2-RF Higher-Order $(\mathrm{H}-\mathrm{O})$ and Restructured Clinical (RC) scales } \\
\hline EID & $14.96 \pm 6.24$ & $13.93 \pm 8.09$ & $11.68 \pm 6.72$ & $F_{2 ; 119}=1.89$ & 0.16 & & & \\
\hline THD & $4.56 \pm 3.84$ & $3.91 \pm 3.51$ & $2.45 \pm 2.96$ & $F_{2 ; 119}=3.54$ & 0.03 & & & \\
\hline BXD & $5.52 \pm 3.30$ & $4.60 \pm 2.76$ & $5.98 \pm 4.68$ & $F_{2 ; 119}=1.78$ & 0.17 & & & \\
\hline $\mathrm{RCd}$ & $8.74 \pm 4.97$ & $7.56 \pm 6.24$ & $5.20 \pm 4.90$ & $F_{2: 119}=3.70$ & 0.03 & & & \\
\hline $\mathrm{RCl}$ & $8.00 \pm 3.28$ & $7.78 \pm 4.70$ & $5.68 \pm 4.19$ & $F_{2 ; 119}=3.54$ & 0.03 & & & \\
\hline $\mathrm{RC2}$ & $5.00 \pm 2.66$ & $4.67 \pm 2.85$ & $4.83 \pm 2.69$ & $F_{2 ; 119}=0.13$ & 0.88 & & & \\
\hline $\mathrm{RC} 3$ & $9.26 \pm 3.05$ & $9.25 \pm 2.84$ & $7.33 \pm 3.79$ & $F_{2 ; 119}=4.83$ & $0.01 *$ & 0.01 & 1.93 & $1.93 *$ \\
\hline RC4 & $4.15 \pm 2.94$ & $3.56 \pm 2.27$ & $5.00 \pm 4.54$ & $F_{2 ; 119}=2.18$ & 0.12 & & & \\
\hline $\mathrm{RC6}$ & $2.56 \pm 2.33$ & $2.25 \pm 2.33$ & $1.48 \pm 1.69$ & $F_{2 ; 119}=2.45$ & 0.09 & & & \\
\hline RC7 & $8.56 \pm 4.59$ & $8.69 \pm 5.15$ & $6.45 \pm 4.67$ & $F_{2 ; 119}=2.73$ & 0.07 & & & \\
\hline $\mathrm{RC} 8$ & $4.44 \pm 3.72$ & $3.31 \pm 3.05$ & $2.28 \pm 3.06$ & $F_{2 ; 119}=3.72$ & 0.03 & & & \\
\hline RC9 & $12.56 \pm 4.64$ & $1 \mathrm{I} .47 \pm 4.23$ & $\mid \mathrm{I} .20 \pm 5.0 \mathrm{I}$ & $F_{2 ; 119}=0.757$ & 0.47 & & & \\
\hline \multicolumn{9}{|c|}{ MMPI-2-RF Somatic/Cognitive and Internalizing Scales } \\
\hline MLS & $4.74 \pm 2.09$ & $2.96 \pm 2.01$ & $2.33 \pm 1.62$ & $F_{2 ; 119}=13.36$ & $<0.00 I^{* *}$ & $1.78^{*}$ & $2.42^{*}$ & 0.64 \\
\hline GIC & $0.93 \pm 1.44$ & $0.80 \pm 1.22$ & $0.40 \pm 1.01$ & $F_{2 ; 119}=1.89$ & 0.16 & & & \\
\hline HPC & $1.85 \pm 1.13$ & $2.07 \pm 1.70$ & $1.20 \pm 1.22$ & $F_{2 ; 119}=4.35$ & 0.02 & & & \\
\hline NUC & $2.59 \pm 1.69$ & $2.31 \pm 1.71$ & $2.23 \pm 1.82$ & $F_{2 ; 119}=0.38$ & 0.69 & & & \\
\hline COG & $3.56 \pm 2.75$ & $2.29 \pm 2.46$ & $1.60 \pm 1.96$ & $F_{2: 119}=5.49$ & $0.01 *$ & 1.27 & $1.96 *$ & 0.69 \\
\hline SUI & $0.56 \pm 0.75$ & $0.49 \pm 0.79$ & $0.15 \pm 0.43$ & $F_{2 ; 119}=3.86$ & 0.02 & & & \\
\hline HLP & $2.59 \pm 1.28$ & $2.22 \pm 1.26$ & $1.40 \pm 0.87$ & $F_{2 ; 119}=9.96$ & $<0.00 I^{* *}$ & 0.37 & $1.19 *$ & $0.82 *$ \\
\hline SFD & $1.11 \pm 1.09$ & $1.13 \pm 1.17$ & $0.60 \pm 0.90$ & $F_{2 ; 119}=3.20$ & 0.04 & & & \\
\hline NFC & $4.85 \pm 2.43$ & $4.45 \pm 2.57$ & $3.00 \pm 2.32$ & $F_{2 ; 119}=5.83$ & $0.004^{*}$ & 0.40 & $1.85^{*}$ & $1.46 *$ \\
\hline STW & $3.22 \pm 1.50$ & $3.20 \pm 1.52$ & $2.75 \pm 1.69$ & $F_{2 ; 119}=1.14$ & 0.33 & & & \\
\hline$A X Y$ & $1.30 \pm 1.10$ & $1.27 \pm 1.27$ & $0.68 \pm 0.86$ & $F_{2 ; 119}=3.99$ & 0.02 & & & \\
\hline ANP & $2.15 \pm 1.79$ & $2.16 \pm 1.61$ & $1.95 \pm 1.74$ & $F_{2 ; 119}=0.21$ & 0.82 & & & \\
\hline BRF & $2.00 \pm 1.21$ & $2.67 \pm 1.83$ & $1.45 \pm 1.43$ & $F_{2 ; 119}=7.02$ & $0.001 * *$ & -0.67 & 0.55 & $1.22 *$ \\
\hline MSF & $3.67 \pm 2.08$ & $4.29 \pm 2.43$ & $3.43 \pm 2.19$ & $F_{2 ; 119}=1.81$ & 0.17 & & & \\
\hline \multicolumn{9}{|c|}{ Externalizing, Interpersonal, and Interest Scales } \\
\hline JCP & $1.37 \pm 1.52$ & $0.91 \pm 0.93$ & $1.43 \pm 1.66$ & $F_{2 ; 119}=2.06$ & 0.13 & & & \\
\hline SUB & $0.48 \pm 0.75$ & $0.36 \pm 1.10$ & $1.00 \pm 1.40$ & $F_{2 ; 119}=3.77$ & 0.03 & & & \\
\hline AGG & $2.44 \pm 1.60$ & $2.05 \pm 1.38$ & $2.15 \pm 1.89$ & $F_{2 ; 119}=0.54$ & 0.59 & & & \\
\hline ACT & $2.78 \pm 1.55$ & $2.65 \pm 1.72$ & $2.33 \pm 1.69$ & $F_{2 ; 119}=0.71$ & 0.50 & & & \\
\hline FML & $2.04 \pm 1.87$ & $1.80 \pm 2.04$ & $2.30 \pm 2.27$ & $F_{2 ; 119}=0.67$ & 0.51 & & & \\
\hline IPP & $2.89 \pm 1.76$ & $2.87 \pm 1.90$ & $3.08 \pm 2.34$ & $F_{2 ; 119}=0.13$ & 0.88 & & & \\
\hline SAV & $2.89 \pm 2.08$ & $3.55 \pm 2.37$ & $3.43 \pm 2.75$ & $F_{2 ; 119}=0.67$ & 0.51 & & & \\
\hline SHY & $2.96 \pm 1.99$ & $2.64 \pm 2.35$ & $2.05 \pm 2.04$ & $F_{2 ; 119}=1.57$ & 0.21 & & & \\
\hline DSF & $0.85 \pm 1.03$ & $0.87 \pm 1.20$ & $0.55 \pm 1.09$ & $F_{2 ; 119}=1.06$ & 0.35 & & & \\
\hline AES & $2.33 \pm 1.66$ & $3.16 \pm 1.86$ & $2.98 \pm 1.70$ & $F_{2 ; 119}=2.03$ & 0.14 & & & \\
\hline MEC & $2.41 \pm 1.85$ & $1.45 \pm 1.41$ & $1.43 \pm 1.63$ & $F_{2 ; 119}=3.89$ & 0.02 & & & \\
\hline \multicolumn{9}{|c|}{ Personality Psychopathology Five (PSY-5) Scales } \\
\hline AGGR-r & $10.56 \pm 2.59$ & $10.07 \pm 2.67$ & $9.85 \pm 3.26$ & $F_{2 ; 119}=0.50$ & 0.61 & & & \\
\hline PSYC-r & $5.00 \pm 3.89$ & $4.24 \pm 3.75$ & $2.75 \pm 3.21$ & $F_{2 ; 119}=3.51$ & 0.03 & & & \\
\hline DISC-r & $5.19 \pm 3.00$ & $4.44 \pm 2.62$ & $5.45 \pm 4.08$ & $F_{2 ; 119}=1.23$ & 0.30 & & & \\
\hline NEGE-r & $8.30 \pm 3.12$ & $8.71 \pm 3.78$ & $6.90 \pm 3.77$ & $F_{2 ; 119}=2.95$ & 0.06 & & & \\
\hline INTR-r & $6.81 \pm 2.94$ & $7.36 \pm 3.23$ & $7.33 \pm 3.61$ & $F_{2 ; 119}=0.28$ & 0.76 & & & \\
\hline
\end{tabular}

Notes: Benjamini-Hochberg correction for multitesting. *Significant for $P<0.05$; **significant for $P<0.0$ I. Tamhane's post hoc tests.

Abbreviations: ACT, Activation; AES, Aesthetic-Literary Interests; AGG, Aggression; AGGR-r, Aggressiveness-revised; ANP, Anger Proneness; AXY, Anxiety; BRF, Behavior-Restricting Fears; BXD, Behavioral/Externalizing Dysfunction; COG, Cognitive Complaints; DISC-r, Disconstraint-revised; DSF, Disaffiliativeness; EID, Emotional/ Internalizing Dysfunction; FML, Family Problems; GIC, Gastrointestinal Complaints; HLP, Helplessness/Hopelessness; HPC, Head Pain Complaints; INTR-r, Introversion/Low Positive Emotionality-revised; IPP, Interpersonal Passivity; JCP, Juvenile Conduct Problems; MEC, Mechanical-Physical Interests; MLS, Malaise; MMPI, Minnesota Multiphasic Personality Inventory-2 Restructured Form; MSF, Multiple Specific Fears; NEGE-r, Negative Emotionality/Neuroticism-revised; NFC, Inefficacy; NUC, Neurological Complaints; PSYC-r, Psychoticism-revised; RCI, Somatic Complaints; RC2, Low Positive Emotions; RC3, Cynicism; RC4, Antisocial Behavior; RC6, Ideas of Persecution; RC7, Dysfunctional Negative Emotions; RC8, Aberrant Experiences; RC9, Hypomanic Activation; RCd, Demoralization; SAV, Social Avoidance; SFD, Self-Doubt; SHY, Shyness; STW, Stress/Worry; SUB, Substance Abuse; SUI, Suicidal/Death Ideation; THD, Thought Dysfunction. 
Table 5 Partial multivariate models (criterion: groups)

\begin{tabular}{|c|c|c|c|c|}
\hline \multirow[t]{2}{*}{ Effect } & \multirow{2}{*}{$\begin{array}{l}\text { Model fitting } \\
\text { criteria } \\
-2 \text { log likelihood }\end{array}$} & \multicolumn{3}{|c|}{ Likelihood ratio tests } \\
\hline & & $\chi^{2}$ & $d f$ & $\mathbf{P}<$ \\
\hline \multicolumn{5}{|c|}{ Likelihood ratio tests } \\
\hline \multicolumn{5}{|l|}{ Model I } \\
\hline Sex & 178.07 & 22.54 & 2 & $<0.001$ \\
\hline Age & 159.30 & 3.76 & 2 & 0.15 \\
\hline Living alone & 165.83 & 10.29 & 2 & 0.01 \\
\hline School $\leq 8$ years & 162.70 & 7.16 & 2 & 0.05 \\
\hline $\begin{array}{l}\text { Physical } \\
\text { comorbidities }\end{array}$ & 169.60 & 14.07 & 2 & 0.001 \\
\hline \multicolumn{5}{|l|}{ Model 2} \\
\hline TRIN-r & 234.17 & 11.37 & 2 & 0.01 \\
\hline F-r & 223.97 & 1.17 & 2 & 0.56 \\
\hline Fs & 225.26 & 2.46 & 2 & 0.29 \\
\hline FBS-r & 225.70 & 2.90 & 2 & 0.24 \\
\hline \multicolumn{5}{|l|}{ Model 3} \\
\hline $\mathrm{RC} 3$ & 210.02 & 2.33 & 2 & 0.31 \\
\hline MLS & 220.26 & 12.57 & 2 & 0.01 \\
\hline COG & 211.51 & 3.82 & 2 & 0.15 \\
\hline HLP & 212.69 & 5.00 & 2 & 0.08 \\
\hline NFC & 208.91 & 1.22 & 2 & 0.54 \\
\hline BRF & 217.20 & 9.51 & 2 & 0.01 \\
\hline
\end{tabular}

Abbreviations: BRF, Behavior-Restricting Fears; COG, Cognitive Complaints; F-r, Infrequent Responses; FBS-r, Symptom Validity; Fs, Infrequent Somatic Responses; HLP, Helplessness/Hopelessness; MLS, Malaise; NFC, Inefficacy; RC3, Cynicism; TRIN-r, True Response Inconsistency.
The factors enlisted as causes of distress in patients with MPM (eg, legal battles for financial compensation and anger toward employers) may cause disappointment and lack of trust among caregivers and patients. Furthermore, feelings of helplessness/hopelessness and behavior-restricting fears are other common features among caregivers who look after patients with MPM. Some studies have supported the concept that younger, relatively poor caregivers who are actively providing care to their relatives for several years may benefit from interventions to improve their QoL. ${ }^{17,21}$

Now we have to consider some limitations to the generalizability of the results. First, the number of patients with MPM was quite low, due to the short survival times. Moreover, some contrasts could not be significant due to the low power of the analyses. Furthermore, the low number of subjects in some groups may have caused wider confidence intervals in the multivariate analysis. Second, despite the fact that we excluded patients with any DSM-IV-TR Axis I or Axis II diagnosis, we did not use well-accepted measures to screen for depressive and anxiety symptomatology. Third, we only used self-report measures that were potentially

Table 6 Multinomial logistic regression analysis: final model (criterion: group differences)

\begin{tabular}{|c|c|c|c|c|c|c|c|c|c|}
\hline \multirow[t]{2}{*}{ Effect } & \multirow{2}{*}{$\begin{array}{l}\text { Model fitting } \\
\text { criteria } \\
-2 \text { log likelihood } \\
\text { of reduced model }\end{array}$} & \multicolumn{3}{|c|}{$\begin{array}{l}\text { Likelihood ratio } \\
\text { tests }\end{array}$} & & \multicolumn{4}{|c|}{$95 \% \mathrm{Cl}$ of odds ratio } \\
\hline & & $\chi^{2}$ & $d f$ & $\boldsymbol{P}<$ & & OR & $\begin{array}{l}\text { Lower } \\
\text { bound }\end{array}$ & $\begin{array}{l}\text { Upper } \\
\text { bound }\end{array}$ & $\boldsymbol{P}<$ \\
\hline \multicolumn{10}{|c|}{ Likelihood ratio tests } \\
\hline \multicolumn{10}{|l|}{ Final model } \\
\hline \multirow[t]{2}{*}{ Women } & 165.31 & 21.34 & 2 & $<0.001$ & Patients & 0.12 & 0.02 & 0.78 & 0.05 \\
\hline & - & - & - & - & First-degree relatives & 3.35 & 0.92 & 12.13 & 0.07 \\
\hline \multirow[t]{2}{*}{ Living alone } & 153.31 & 9.35 & 2 & 0.01 & Patients & 0.08 & 0.01 & 0.51 & 0.01 \\
\hline & - & - & - & - & First-degree relatives & 0.20 & 0.05 & 0.80 & 0.05 \\
\hline \multirow[t]{2}{*}{ School $\leq 8$ years } & 150.64 & 6.67 & 2 & 0.05 & Patients & 1.26 & 0.18 & 8.93 & 0.82 \\
\hline & - & - & - & - & First-degree relatives & 5.16 & 1.12 & 23.82 & 0.05 \\
\hline Physical & 157.36 & 13.39 & 2 & 0.001 & Patients & 27.43 & 3.17 & 237.50 & 0.01 \\
\hline comorbidities & - & - & - & - & First-degree relatives & 1.25 & 0.40 & 3.89 & 0.70 \\
\hline \multirow[t]{2}{*}{ TRIN-r } & 153.39 & 9.42 & 2 & 0.01 & Patients & 1.99 & 1.22 & 3.22 & 0.01 \\
\hline & - & - & - & - & First-degree relatives & 1.23 & 0.87 & 1.74 & 0.24 \\
\hline \multirow[t]{2}{*}{ MLS } & 156.75 & 12.78 & 2 & 0.01 & Patients & 1.88 & 1.15 & 3.08 & 0.05 \\
\hline & - & - & - & - & First-degree relatives & 0.90 & 0.64 & 1.27 & 0.55 \\
\hline \multirow[t]{2}{*}{ BRF } & 149.26 & 5.29 & 2 & 0.07 & Patients & 0.73 & $0.4 I$ & 1.31 & 0.29 \\
\hline & - & - & - & - & First-degree relatives & 1.22 & 0.84 & 1.76 & 0.30 \\
\hline \multirow[t]{4}{*}{ Physical health } & 147.24 & 3.27 & 2 & 0.20 & Patients & 0.98 & 0.92 & 1.05 & 0.60 \\
\hline & - & - & - & - & First-degree relatives & 0.96 & 0.91 & 1.01 & 0.10 \\
\hline & & & & & & \multicolumn{3}{|c|}{ Pearson } & \multirow[t]{2}{*}{ Nagelkerke $R^{2}$} \\
\hline & -2 log likelihood & & & & & $x^{2}$ & $d f$ & $\mathbf{P}<$ & \\
\hline \multicolumn{10}{|c|}{ Final model fitting statistics } \\
\hline & 101.27 & 101.27 & 16 & $<0.001$ & & 342.46 & 216 & $<0.001$ & 0.66 \\
\hline
\end{tabular}

Abbreviations: BRF, Behavior-Restricting Fears; Cl, confidence interval; MLS, Malaise; OR, odds ratio; TRIN-r, True Response Inconsistency. 
affected by social desirability bias, and - despite the validity of all the MMPI protocols - our results have shown some differences between groups for scales of validity, with patients and caregivers having higher scores than controls. Fourth, controls differed between patients and their relatives for several socio-demographic variables, even after controlling for other variables. Nevertheless, our research is the first systematic study investigating personality traits and QoL in MPM patients and their relatives who provide direct care.

\section{Conclusion}

Patients with MPM have poorer physical health, and they report a general feeling of malaise, cognitive symptoms, inefficacy, helplessness, and hopelessness. Caregivers, meanwhile, often report feelings of inefficacy and helplessness, and they lack trust in people. Due to the fact that the QoL of family caregivers and patients with cancer can vary along the illness trajectory, ${ }^{22}$ health care providers should assess the ongoing adjustment and emotional wellbeing of people with MPM and their relatives. After all, poorly recognized distress could lead to difficulties in making decisions about treatment, and poor adherence to medical treatment, and among family caregivers, lower engagement in health behaviors, such as cancer screening. Family-based psychoeducational programs and support groups for people affected by MPM and their family members may help to reduce the distress in patients and caregivers, improving their quality of life and lowering levels of caregiver burden. ${ }^{23,24}$ Nevertheless, to date, we have no controlled studies investigating the effectiveness of psychological interventions aimed to reduce emotional distress in MDM patients and their caregivers. Thus, future research is needed to identify guidelines for psychological best practices (through process and outcome studies). In this perspective, the assessment of personality traits in MDM patients and their caregivers could orient the intervention, with the aims of activating and reinforcing adherence to treatment and improving QoL.

\section{Acknowledgment}

This study was sponsored by the Department of Health of Alessandria, to the Post Graduate School in Clinical Psychology of the University of Turin; it was approved by the University of Turin, Piedmont Region, as well as by the townships of Casale Monferrato and Monfalcone.

\section{Disclosure}

The authors report no conflicts of interest in this work.

\section{References}

1. Case BW, Abraham JL, Meeker G, Pooley FD, Pinkerton KE. Applying definitions of "asbestos" to environmental and "low-dose" exposure levels and health effects, particularly malignant mesothelioma. JToxicol Environ Health B Crit Rev. 2011;14(1-4):3-39.

2. Myers R. Asbestos-related pleural disease. Curr Opin Pulm Med. 2012;18(4):377-381.

3. Peto J, Decarli A, La Vecchia C, Levi F, Negri E. The European mesothelioma epidemic. Br J Cancer. 1999;79(3-4):666-672.

4. Marinaccio A, Binazzi A, Marzio DD, et al; ReNaM Working Group. Pleural malignant mesothelioma epidemic: incidence, modalities of asbestos exposure and occupations involved from the Italian National Register. Int J Cancer. 2012;130(9):2146-2154.

5. Mirabelli D, Cavone D, Merler E, et al. Non-occupational exposure to asbestos and malignant mesothelioma in the Italian National Registry of Mesotheliomas. Occup Environ Med. 2010;67(11):792-794.

6. Montanaro F, Rosato R, Gangemi M, et al. Survival of pleural malignant mesothelioma in Italy: a population-based study. Int J Cancer. 2009;124(1):201-207.

7. Moore S, Darlison L, Tod AM. Living with mesothelioma. A literature review. Eur J Cancer Care (Engl). 2010;19(4):458-468.

8. Muers MF, Stephens RJ, Fisher P, et al; MS01 Trial Management Group. Active symptom control with or without chemotherapy in the treatment of patients with malignant pleural mesothelioma (MS01): a multicentre randomised trial. Lancet. 2008;371(9625):1685-1694.

9. Nowak AK, Stockler MR, Byrne MJ. Assessing quality of life during chemotherapy for pleural mesothelioma: feasibility, validity, and results of using the European Organization for Research and Treatment of Cancer Core Quality of Life Questionnaire and Lung Cancer Module. J Clin Oncol. 2004;22(15):3172-3180.

10. American Psychiatric Association. Diagnostic and Statistical Manual of Mental Disorders. Text Revision. 4th ed. Washington, DC: American Psychiatric Association; 2000.

11. Barbieri PG, Marinaccio A, Ferrante P, Scarselli A, Pinelli V, Tassi G. Effects of combined therapies on the survival of pleural mesothelioma patients treated in Brescia, 1982-2006. Tumori. 2012;98(2):215-219.

12. The World Health Organization Quality of Life Assessment (WHOQOL): development and general psychometric properties. Soc Sci Med. 1998;46(12):1569-1585.

13. Ben-Porath YS, Tellegen A. MMPI-2-RF (Minnesota Multiphasic Personality Inventory - 2 - Restructured Form) Manual for Administration, Scoring, and Interpretation. Minneapolis, MN: University of Minnesota Press; 2008.

14. Sirigatti S, Faravelli C. MMPI-2-RF: Adattamento Italiano. Taratura, Proprietà Psicometriche e Correlati Empirici [MMPI-2-RF: Italian Version. Psychometric properties and empirical correlates.] Firenze: Giunti OS; 2012. Italian.

15. Benjamini Y, Hochberg Y. Controlling the false discovery rate: a practical and powerful approach to multiple testing. J R Statist Soc B. 1995;57(1):289-300.

16. Chen ML, Chu L, Chen HC. Impact of cancer patients' quality of life on that of spouse caregivers. Support Care Cancer. 2004;12(7): 469-475.

17. Kim Y, Spillers RL. Quality of life of family caregivers at 2 years after a relative's cancer diagnosis. Psychooncology. 2010;19(4):431-440.

18. Cordes ME, Brueggen C. Diffuse malignant pleural mesothelioma: part II. Symptom management. Clin J Oncol Nurs. 2003;7(5):545-552.

19. Barak Y, Achiron A, Rotstein Z, Elizur A, Noy S. Stress associated with asbestosis: the trauma of waiting for death. Psychooncology. 1998;7(2): 126-128.

20. Ingram PB, Kelso KM, McCord DM. Empirical correlates and expanded interpretation of the MMPI-2-RF Restructured Clinical Scale 3 (Cynicism). Assessment. 2011;18(1):95-101.

21. Kim Y, Spillers RL, Hall DL. Quality of life of family caregivers 5 years after a relative's cancer diagnosis: follow-up of the national quality of life survey for caregivers. Psychooncology. 2012;21(3):273-281. 
22. Kim Y, Given BA. Quality of life of family caregivers of cancer survivors: across the trajectory of the illness. Cancer. 2008;112(Suppl 11): 2556-2568.

23. Chapman E, Hughes D, Landy A, Whale J, Saunders M. Challenging the representations of cancer pain: experiences of a multidisciplinary pain management group in a palliative care unit. Palliat Support Care. 2005;3(1):43-49.
24. Moore S, Teehan C, Cornwall A, Ball K, Thomas J. 'Hands of Time': the experience of establishing a support group for people affected by mesothelioma. Eur J Cancer Care (Engl). 2008;17(6):585-592.

\section{Publish your work in this journal}

Neuropsychiatric Disease and Treatment is an international, peerreviewed journal of clinical therapeutics and pharmacology focusing on concise rapid reporting of clinical or pre-clinical studies on a range of neuropsychiatric and neurological disorders. This journal is indexed on PubMed Central, the 'PsycINFO' database and CAS.

The manuscript management system is completely online and includes a very quick and fair peer-review system, which is all easy to use. Visit http://www.dovepress.com/testimonials.php to read real quotes from published authors.

\footnotetext{
Submit your manuscript here: http://www.dovepress.com/neuropsychiatric-disease-and-treatment-journal
} 